\title{
Domains and naïve theories
}

\author{
Susan A. Gelman* and Nicholaus S. Noles
}

\begin{abstract}
Human cognition entails domain-specific cognitive processes that influence memory, attention, categorization, problem-solving, reasoning, and knowledge organization. This article examines domain-specific causal theories, which are of particular interest for permitting an examination of how knowledge structures change over time. We first describe the properties of commonsense theories, and how commonsense theories differ from scientific theories, illustrating with children's classification of biological and nonbiological kinds. We next consider the implications of domain-specificity for broader issues regarding cognitive development and conceptual change. We then examine the extent to which domain-specific theories interact, and how people reconcile competing causal frameworks. Future directions for research include examining how different content domains interact, the nature of theory change, the role of context (including culture, language, and social interaction) in inducing different frameworks, and the neural bases for domain-specific reasoning. @ 2010 John Wiley \& Sons, Ltd. WIREs Cogn Sci 20112 490-502 DOI: 10.1002/wcs.124
\end{abstract}

\section{INTRODUCTION}

$\mathrm{H}$ uman cognition has classically been understood in terms of domain-general processes such as perception, attention, memory, categorization, logical reasoning, and associative learning. These processes apply broadly across knowledge domains, reflecting psychological principles that transcend content. For example, there is a domain-general constraint on short-term memory such that when presented with a new list of items, people can recall only $7 \pm 2$ pieces of information, regardless of whether the items on the list are numbers, chess pieces, or Pokémon characters. ${ }^{1}$ Discovering general principles of cognition is an important goal of research.

Although domain-general processes are fundamental, they cannot provide a complete portrait of human thought. Cognitive processes and their developmental paths are highly uneven across domains. For example, consider the stark contrast between learning language and learning calculus. Most children master the principles of syntax within the first five years of life, whereas vanishingly few children learn calculus during that period. These different developmental paths do not reflect a simple difference in the complexity

*Correspondence to: gelman@umich.edu

Department of Psychology, University of Michigan, Ann Arbor, MI, USA

DOI: $10.1002 /$ wcs. 124 or difficulty of syntax versus calculus, because syntax is actually acquired more easily in childhood than adulthood, whereas calculus shows the reverse (and more typical) developmental pattern. More generally, although many types of knowledge are acquired more easily by adults than children (including higher mathematics, political and legal systems, medical treatment of disease, or historical forces affecting social movements), other types of knowledge are acquired more easily in childhood than adulthood (such as syntax, phonology, perhaps music), and even demonstrate a sensitive period of learning in childhood. ${ }^{2}$ Thus, the process of learning requires consideration of the content of what is being learned.

\section{IMPORTANCE OF DOMAIN-SPECIFIC KNOWLEDGE}

Domain-specific content knowledge influences a vast scope of cognitive activities, including: what we attend to (e.g., faces versus nonface displays), ${ }^{3}$ what we remember (e.g., events that are congruent versus incongruent with stereotypes), ${ }^{4}$ how we categorize (e.g., animals versus human-made artifacts), ${ }^{5}$ what we imitate, ${ }^{6}$ and future-based reasoning (e.g., predictions regarding behavior of humans versus machines). ${ }^{7}$ For example, although memory is constrained in domaingeneral ways, domain-specific knowledge structures influence how much gets chunked into a single unit, 
resulting in stunning variation in recall as a function of expertise. Chess experts possess better recall for chess pieces than do chess novices, but this advantage is strongly attenuated if the pieces are in random positions that do not naturally occur during chess matches. ${ }^{8}$ An individual can even be trained to stretch their digit span to as much as 10 times the average span, simply by engaging in extensive practice with chunking. ${ }^{9}$

Although the fact of domain-specificity is uncontentious, how best to explain domain-specificity incites more controversy. We illustrate with the case of logical reasoning. For many years, researchers assumed that logical reasoning rules (e.g., modus ponens) are acquired as domain-general principles in adulthood. ${ }^{10}$ However, performance on logical reasoning tasks varies dramatically as a function of how the problem is framed. When presented in a context-free manner, adults consistently err in applying certain logical principles. ${ }^{11}$ For example, when asked to verify the rule 'If a card has a vowel on one side, it has an even number on the other side' (logically represented as $\mathrm{P} \rightarrow \mathrm{Q}$ ), people consistently show a bias to check to see if cards with vowels have even numbers ( $\mathrm{P}$; good), and if cards with even numbers have vowels (Q; error, as they should check to see if cards with odd numbers have vowels, in other words, $\sim$ Q). In contrast, when the logically identical problem is framed in terms of rules for drinking ('If a person buys a beer, they are at least 18 years of age'), people correctly check to see if people buying beer are 18 (P; good), and if people who are NOT 18 are buying beer ( $\sim$; good) (see Figure 1). Some have proposed that this domain-specific response arises out of general principles involving familiarity and experience (greater experience with certain kinds of rules leads to better use of the logical principles), ${ }^{12}$ whereas others have argued that it arises out of evolved socialreasoning capacities to detect cheaters. Thus, even with wholly novel content, if the problem is framed as one in which there is a social contract, and individuals are attempting to violate the rules of the social contract, then correct performance is more likely. ${ }^{13}$

There are at least three distinct ways of construing domain-specific cognition, each with different assumptions regarding innateness, the role of input, and outcome variability. ${ }^{14}$ These are modularity, expertise, and theory perspectives (see Table 1). Each perspective can best account for some

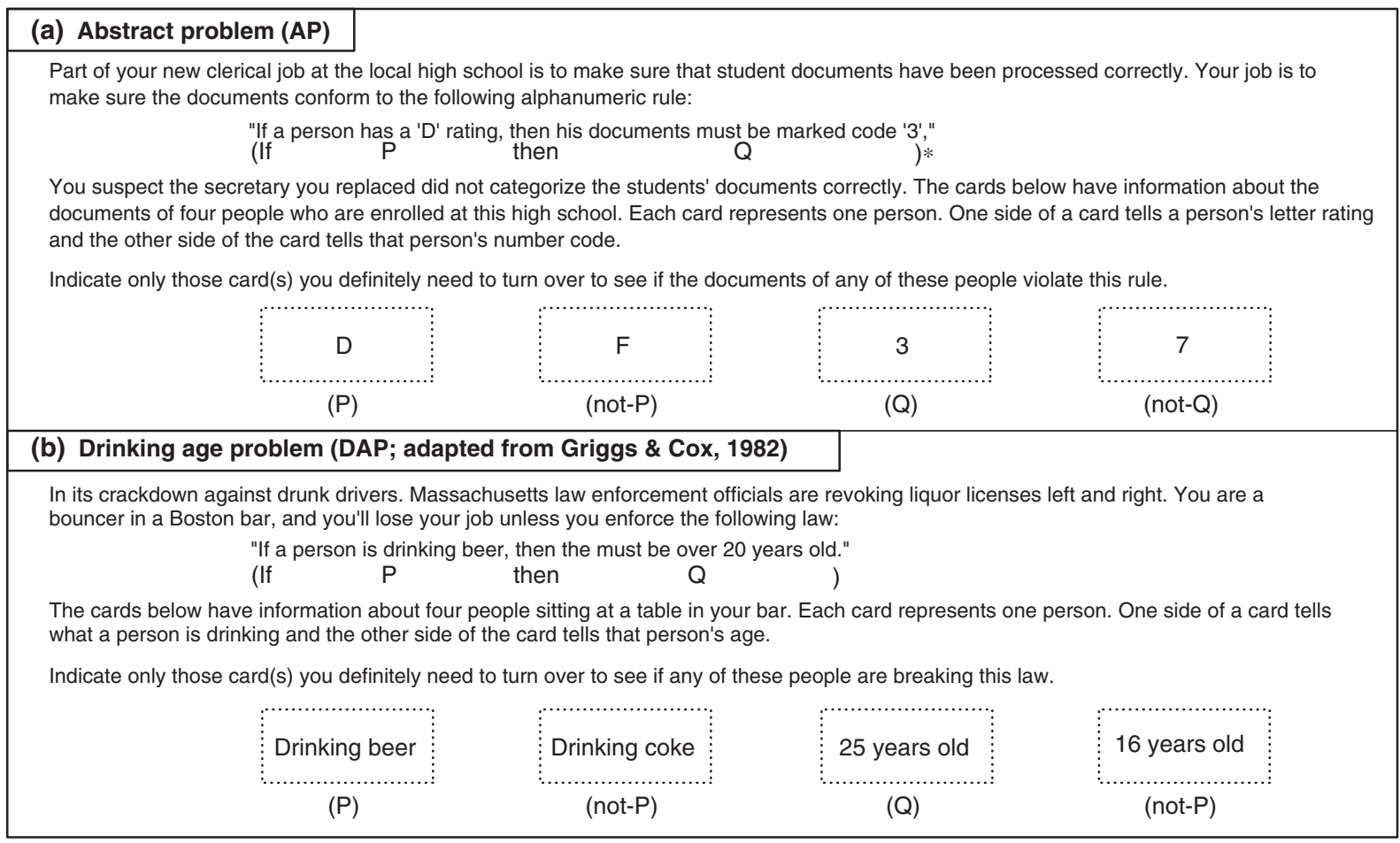

*The logical categories ( $P$ s and $Q s$ ) marked on the rules and cards are here only for the reader's benefit; they never appear an problems given to subjects.

FIG URE 1 | Examples of content-specific effects on a logical reasoning task (the Wason selection task). Although the logical solution is the same for both scenarios, differences in contextual framing yield different response patterns. (Reprinted with permission from Ref 13. Copyright 1989 Elsevier.) 
TABLE 1 | Three Ways of Construing Domain-Specific Cognition (Reprinted with permission from Ref 14. Copyright 1998 Wiley-Blackwell)

\begin{tabular}{|c|c|c|c|c|c|}
\hline \multicolumn{6}{|c|}{ A Schematic Comparison among Modular, Theory Theory, and Expertise Approaches } \\
\hline & Mechanism & Role of Input & What is Innate & Variability in Outcome & Sample Domains \\
\hline Modules & Biological constraints & Input as 'trigger' & $\begin{array}{l}\text { Mandatory input-output } \\
\text { systems }\end{array}$ & $\begin{array}{l}\text { Highly fixed and } \\
\text { constrained }\end{array}$ & $\begin{array}{l}\text { Language, vision, theory of } \\
\text { mind }\end{array}$ \\
\hline Theories & $\begin{array}{l}\text { Causal-explanatory } \\
\text { understandings }\end{array}$ & $\begin{array}{l}\text { Input as source of } \\
\text { data }\end{array}$ & $\begin{array}{l}\text { Skeletal principles and } \\
\text { ontologies }\end{array}$ & $\begin{array}{l}\text { Variable within broad } \\
\text { constraints }\end{array}$ & $\begin{array}{l}\text { Psychology, physics, } \\
\text { biology }\end{array}$ \\
\hline Expertise & $\begin{array}{l}\text { Information-processing } \\
\text { skills }\end{array}$ & $\begin{array}{l}\text { Input/experience } \\
\text { foundational }\end{array}$ & $\begin{array}{l}\text { Information-processing } \\
\text { strategies }\end{array}$ & Highly variable & Reading, dinosaurs, physics \\
\hline
\end{tabular}

of the phenomena of interest, and all are critical to a complete understanding of domain-specificity.

The modularity perspective posits that evolutionary pressures have gradually resulted in brain regions functionally dedicated to certain biologically constrained processes. For example, studies of face perception have revealed that the processes by which faces are perceived and recognized are localized to specific portions of the brain referred to collectively as the fusiform face area (FFA). ${ }^{15}$ Other examples of modularity include concepts of number ${ }^{16}$ and certain aspects of language acquisition (notably phonology and syntax). ${ }^{17}$ These proposed specialized neurological structures provide innate, domain-specific processing that emerges with little experience and develops according to a highly constrained and predictable developmental pattern. ${ }^{18}$ At the same time, however, it is important to note that functional localization per se is neither necessary nor sufficient for modularity.

Although the modularity perspective posits universal, neurologically localized, and innate systems, the expertise perspective posits that extensive experience can lead to qualitative changes in cognitive skills (see the work of Ericsson ${ }^{19}$ for a review). The first time a teenager drives a car, he/she must explicitly monitor his/her environment, think about how hard he/she is pushing the pedals or turning the wheel, and remember the rules of the road and the path to his/her destination. After years of experience, drivers perform these tasks with very little explicit thought or attention. A similar process occurs for new readers. At first, they identify individual letters and say them aloud, but soon they are experiencing text in a much different way, absorbing whole words and sentences faster than they can speak. Learning to drive or to read fundamentally changes the way that individuals experience these domains. However, expertise in one area does not readily cross domain boundaries. Being a skilled driver does not positively or negatively influence reading comprehension, for example.

Finally, the theory perspective involves both early emerging and experience-based components.
Initially, children rely on relatively sparse theories relating to ontologies and other domain-specific principles (e.g., theory of mind or theory of physical objects). However, as they collect evidence through everyday experiences with the world, as well as interactions with others in social contexts, children amend and expand their intuitions into more complex and comprehensive causal-explanatory understandings. ${ }^{20}$ For example, children's concept of support-that one object holds up another-is very coarse early in development, but as they gain experience their theories adapt to account for the permutations in the nature of contact and weight distribution. ${ }^{21}$

In this article, we focus primarily on domainspecific causal theories, which are of particular interest for permitting an examination of how knowledge structures change over time. We first describe the properties of commonsense theories, and how commonsense theories differ from scientific theories, illustrating with an examination of children's intuitive classification of living things. We next consider the implications of domain-specificity for broader issues regarding cognitive development and conceptual change. We then examine the extent to which domain-specific theories interact (or not), and how children reconcile competing causal frameworks. Finally, we summarize and conclude.

\section{COMMONSENSE THEORIES}

In this section, we review the components of commonsense theories (also known as folk or naïve theories), clarify the distinction between commonsense theories and scientific theories, and provide examples of how commonsense theories are instantiated in human classifications from an early age.

Components of a commonsense theory. Carey ${ }^{22}$ noted that commonsense theories have three key components (Table 2): ontological commitments, causal laws, and coherence. Ontological commitments specify what sorts of entities participate in a theory; for example, mental states in a theory of psychology or 
TABLE 2 | Components of a Commonsense Theory, with Examples (Reprinted with permission from Ref 22. Copyright 1985 Wiley-Blackwell)

\begin{tabular}{|c|c|c|c|}
\hline & Biology & Physics & Psychology \\
\hline Ontological commitments & Animals, parents & Physical objects & Thoughts, desires \\
\hline Causal laws & $\begin{array}{l}\text { Eating food causes animals to } \\
\text { grow }\end{array}$ & $\begin{array}{l}\text { One object colliding with another } \\
\text { object causes it to move }\end{array}$ & $\begin{array}{l}\text { Beliefs and desires cause } \\
\text { individuals to act }\end{array}$ \\
\hline Coherence & $\begin{array}{l}\text { Living and dying are reciprocal } \\
\text { processes. If something can } \\
\text { live, then it can die }\end{array}$ & $\begin{array}{l}\text { Unsupported objects fall from up to } \\
\text { down, but supported objects are } \\
\text { solid and stable }\end{array}$ & $\begin{array}{l}\text { Acts are intentional when people } \\
\text { are awake and accidental when } \\
\text { they are asleep }\end{array}$ \\
\hline Unobservables & Essence & Gravity & Goals \\
\hline
\end{tabular}

elements in a theory of chemistry. The very same object can be construed from multiple ontological perspectives: in a psychological theory, a dog is understood in terms of its thoughts, motives, and personality; in a biological theory, a dog is understood in terms of its multiple bodily systems (digestive, circulatory) and evolutionary past; in a physical theory, a dog is understood in terms of its weight, mass, and momentum. Similarly, a $\$ 20$ bill is a flammable piece of paper in a physical theory, but a unit of exchange in an economic theory. So, ontological commitments provide the broad perspective and elements that one considers in thinking about an entity. Children are sensitive to ontological distinctions from infancy, expecting, for example, that the conditions leading to object motion will differ for people versus inanimate objects. ${ }^{23}$

Causal laws form the framework for the knowledge structures that each theory contains. In a psychological theory, thoughts and beliefs are the underlying motivations to a person's behavior. In a biological theory, ingestion of food leads to an increase in body weight. In a physical theory, energy is transferred from one ball to another when two balls collide. One key difference between a theory and other kinds of knowledge structures (such as taxonomies or scripts) is that theories require causal understandings. Thus, one could possess a script for what one does at a birthday party that involves a detailed set of rules regarding what happens when, but a script need not include any information about how these features are causally linked. In forming causal laws and expectations, children and adults are particularly sensitive to statistical patterns of cooccurrence and make use of these cues to draw rich causal inferences. For example, Kushnir and Gopnik ${ }^{24}$ presented children with a machine that lights up and plays sounds when certain objects are placed on top of it. Children were exquisitely sensitive to the regularity with which blocks caused the box to light up and make sounds, exhibiting the ability to consistently select the block that 'made the box go' at higher rates (see Figure 2). At the same time, children's judgments were also influenced by whether the person acting upon the object was the child him/herself or another person. Actions performed by the self were given more weight, reflecting intuitive theoretical beliefs concerning who can provide a more effective action.

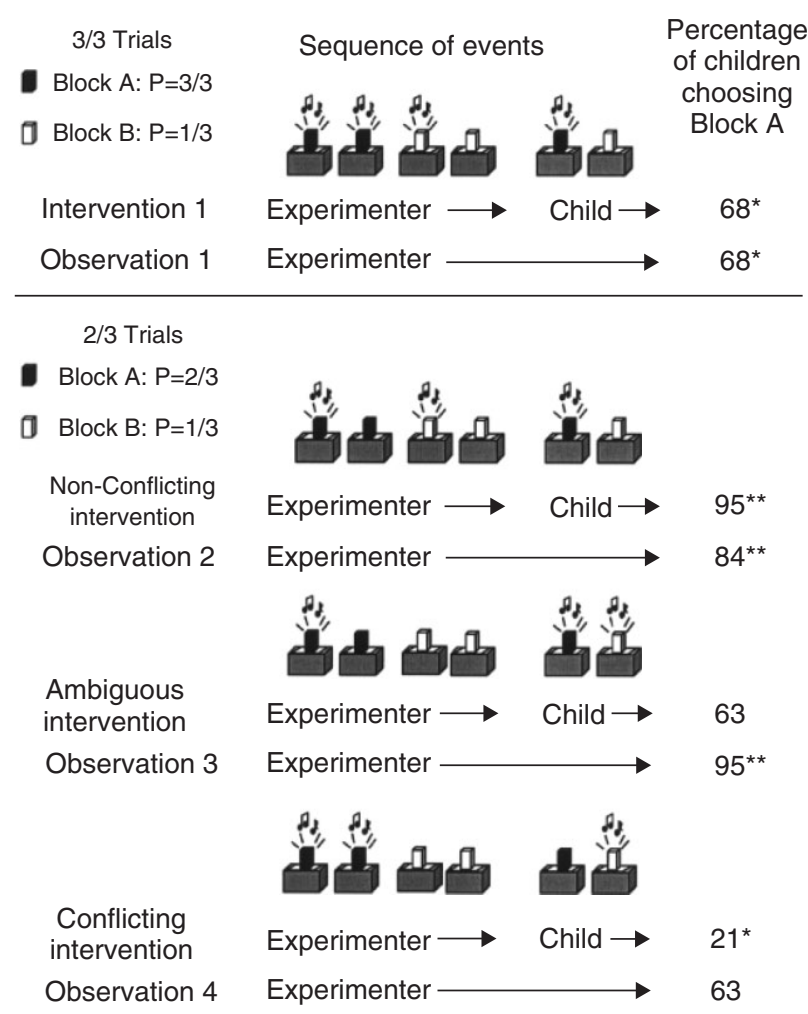

FIG URE 2 | Summary of experimental trials examining children's sensitivity to statistical information in forming causal expectations. In $3 / 3$ trials, children learned that Block A reliably set off the detector and they selected that block as the cause at rates significantly greater than chance. Children were sensitive to the probability that each block would activate the detector, but their selections were also influenced by their own actions. As can be seen in the 2/3 trials, children employed statistical regularities when they observed the experimenter activating the detector, but when their own experience activating the detector was at odds with the overall statistical regularity of the entire trial, they relied on their own personal action on the detector rather than statistical regularities alone. (Reprinted with permission from Ref 24. Copyright 2005 SAGE Publications.) 
Beyond simply identifying cause and effect relationships, children and adults treat causal features as more central than other (noncausal) features. This prioritization of causes is referred to as the 'causal status hypothesis'. ${ }^{25}$ For example, if eating fruit causes an animal called a rooban to have sticky feet that enable them to climb trees, then eating fruit is a central feature of the rooban because the remaining features of the rooban are effects of their diet. Consequently, a creature that eats fruit but does not climb trees (thereby retaining the causal feature) is more likely to be identified as a rooban than a creature that eats meat and climbs trees (thereby retaining the effect feature; see Table 3 for examples in other domains). Children and adults attend to causal features in both knowledgerich domains and simplified domains about which participants have minimal knowledge. ${ }^{26,27}$

Coherence indicates that various beliefs are interrelated, and not simply isolated propositions. To these three components, we would also add that theories include unobservable constructs. Gravity is unobservable, but even infants have some sense that an unseen force acts on objects: unsupported objects are expected to fall to the ground; they do not hang suspended in the air. Children appeal to this unobservable construct even before they have a full understanding of the rules of support (see Figure 3 for how this understanding changes with age). ${ }^{21}$ Furthermore, unobserved features are not limited to physical theories, but extend to include postulated entities, such as thoughts and desires (in a psychological theory) ${ }^{28}$ and essences (in a biological theory). ${ }^{29}$

Commonsense theories versus scientific theories. Commonsense theories, though importantly similar to scientific theories, differ from scientific theories in several key respects. First, commonsense theories are formulated at an abstract, global level. Wellman ${ }^{28}$ makes a distinction between a framework theory and a specific theory. He gives the example of behaviorism as a framework theory within the domain of psychology, and the Rescorla-Wagner theory of classical conditioning as a specific theory within the framework theory of behaviorism. Whereas specific theories are directly tested and modified via experimental evidence, framework theories embody a set of theoretical assumptions that are not as easily changed on the basis of empirical evidence. Commonsense theories are akin to framework theories, not specific theories.

Second, commonsense theories are rarely tested rigorously. A scientist formulates precise and explicitly formulated hypotheses, designs experiments that systematically modify the variables under study, and precisely evaluates the evidence to determine the empirical support for the theory. A layperson rarely engages in these processes, instead generating hypotheses that are less formal, and evaluating evidence in a more piecemeal manner. Indeed, one very important developmental change is the ability to test and evaluate

TABLE 3 | Example Domains and Features (Reprinted with permission from Ref 25. Copyright 2000 Elsevier)

\begin{tabular}{|c|c|c|c|c|}
\hline \multirow[b]{2}{*}{ Domains } & \multicolumn{3}{|c|}{ Types of Features } & \multirow[b]{2}{*}{ Causal Background Information } \\
\hline & $X$ & Y & Z & \\
\hline Animal (roobans) & Eat fruits & Have sticky feet & $\begin{array}{l}\text { Build nests on } \\
\text { trees }\end{array}$ & $\begin{array}{l}\text { Eating fruits tends to cause roobans to have sticky feet because } \\
\text { sugar in fruits is secreted through pores under their feet. Having } \\
\text { sticky feet tends to allow roobans to build nests on trees } \\
\text { because they can climb up the trees easily with sticky feet }\end{array}$ \\
\hline Disease (Covition) & $\begin{array}{l}\text { Blurred } \\
\text { vision }\end{array}$ & Headache & Insomnia & $\begin{array}{l}\text { Blurred vision tends to cause Covition patients to have a headache } \\
\text { A headache tends to cause Covition patients to suffer from } \\
\text { insomnia }\end{array}$ \\
\hline Tribe (Hino) & Farming & Many leaders & Monotheistic & $\begin{array}{l}\text { Relying on farming tends to cause Hino tribes to have many leaders } \\
\text { because large-scale farming requires specialized decisions that } \\
\text { must be co-ordinated by many leaders. Having many leaders, in } \\
\text { turn, tends to cause Hino tribes to be monotheistic because } \\
\text { unity under a single deity prevents squabbling and fighting for } \\
\text { power among the many tribe leaders }\end{array}$ \\
\hline $\begin{array}{l}\text { Car (Romanian } \\
\text { Rogo) }\end{array}$ & $\begin{array}{l}\text { Use butane- } \\
\text { laden fuel }\end{array}$ & $\begin{array}{l}\text { Hot engine } \\
\text { temperature }\end{array}$ & $\begin{array}{c}\text { Loose gas } \\
\text { gasket }\end{array}$ & $\begin{array}{l}\text { Butane-laden fuel in a Romanian Rogo tends to cause hot engine } \\
\text { temperatures. The butane in the fuel burns at a hotter } \\
\text { temperature than normal gasoline. Hot engine temperatures in } \\
\text { a Romanian Rogo tends to cause a gas gasket to become loose. } \\
\text { The heat in the engine makes the rubber around the gas gasket } \\
\text { melt and become loose }\end{array}$ \\
\hline
\end{tabular}

Causal features (in the $\mathrm{X}$ column) are more useful in making inductive inferences than features that are effects. 


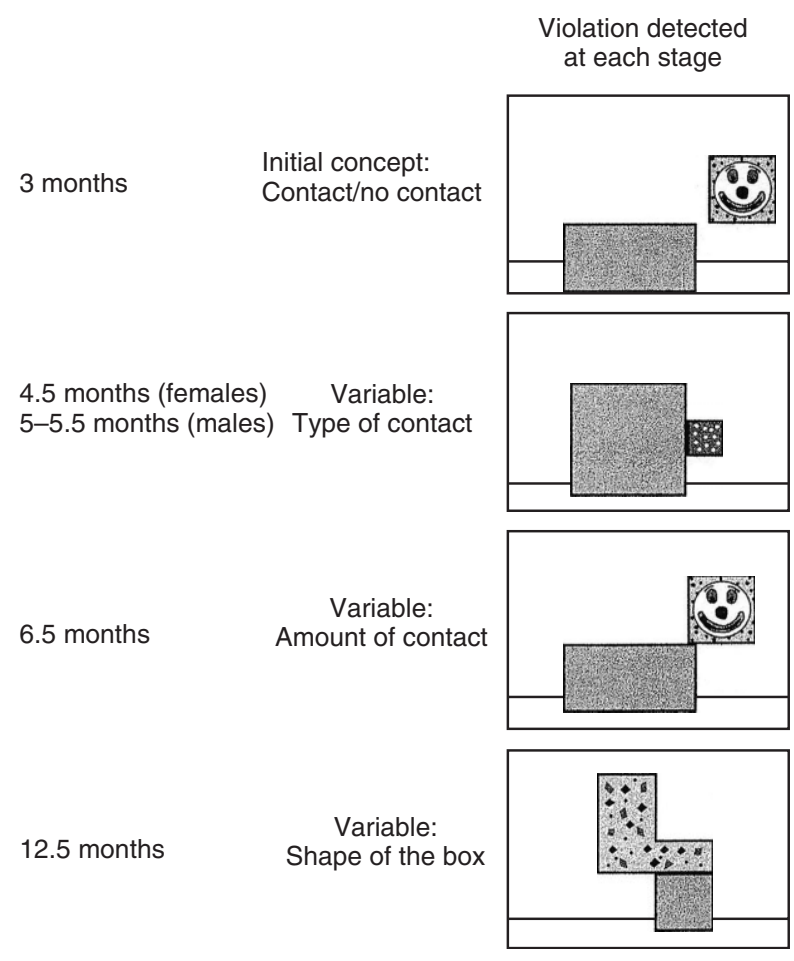

FIG URE 3 | The development of infant knowledge about support during their first year as reported by Baillargeon. ${ }^{21}$ (Reprinted with permission from Ref 21. Copyright 1998 The International Union of Psychological Science.)

theories in a methodical, scientific manner (Figure 4). This is not to say that children ignore empirical evidence; to the contrary, consideration of evidence is key to all theories, scientific or commonsense. ${ }^{20}$ Rather, children consider and evaluate data in a qualitatively different manner than scientists.

Finally (and most obviously), while scientific theories are (by definition) created by adult scientists, commonsense theories require no specialized knowledge and are constructed (or begin to be constructed) early in childhood. Consequently, it is likely that the sociological context of theory construction is quite different for scientific theories (involving collaborations within and across research teams systematically formulating and testing explicit hypotheses) than for a child attempting to understand the world with input from multiple, often implicit sources (parent, school, peers, informal observations). ${ }^{31}$ (In the section entitled 'Interactions Among Domains', we address the additional question of whether scientists also retain their commonsense theories, alongside the scientific theories they have constructed.)

Which theories and how many theories children possess at different ages are open questions, although most researchers would credit children with at least a naïve physics and a naïve psychology from infancy, and some would also credit children with a naïve biology from an early age. ${ }^{14,32}$

Evidence for commonsense theories: Biological classification as a case study. There is a rich array of research findings demonstrating that domain-specific commonsense theories affect cognition from early in life. We illustrate by considering the classification of animals within a naïve biological theory. The ontological commitments of a naïve biology include a distinction between living and nonliving things, and between plants and animals, as well as an assumption that there are distinctly different kinds of animals (e.g., birds, fish, dogs, and llamas are all qualitatively different kinds). ${ }^{33}$ The causal processes that are key to a naïve biology entail inherent, selfdirected change not reducible either to intentional action (which is psychological) or mechanical action (which is physical). These processes would include, for example, growth, healing, and processing nutrients. The coherence evident in a naïve biology tells us, for example, that life and death are reciprocal processes, or that elements that lead to illness must be reversed to yield a cure. Finally, unobservable constructs in a naïve biology might include the notion of a category essence, ${ }^{29}$ vitalism, ${ }^{32}$ or genes.

The importance of domain-specific theories can be seen in children's categorization of the biological world, and how it differs from their categorization in other domains. As Stephen Jay Gould wrote, p. 98, 'Classifications are theories about the basis of natural order, not dull catalogues compiled only to avoid chaos'. ${ }^{34}$ When categorizing, children view distinctions between different animal species as natural and objective, whereas they view distinctions between different artifact species as conventional and subjective. ${ }^{35}$ This distinction has numerous consequences for children's behavior and choices. For categories of animals, children recognize that appearances can be deceiving. ${ }^{36}$ At the same time, children understand that category membership is unchanging in the face of purely superficial transformations (e.g., a lion wearing a tiger costume is still a lion), and yet for artifacts, superficial changes often can and do change the identity of an object (e.g., a coffeepot with an opening cut out becomes a birdfeeder). ${ }^{37}$ Children are also more likely to view membership in a category as absolute for animals but "graded" for artifacts. ${ }^{38}$ For example, they recognize that an ostrich is an atypical bird, yet they deny that it is "sort of" a bird, insisting that it is fully, $100 \%$ a bird. In contrast, they recognize that a headband is an atypical piece of clothing and further judge it to be "sort of" a piece of clothing (not fully, not $100 \%$ clothing). They object to the possibility of grouping together members of two 


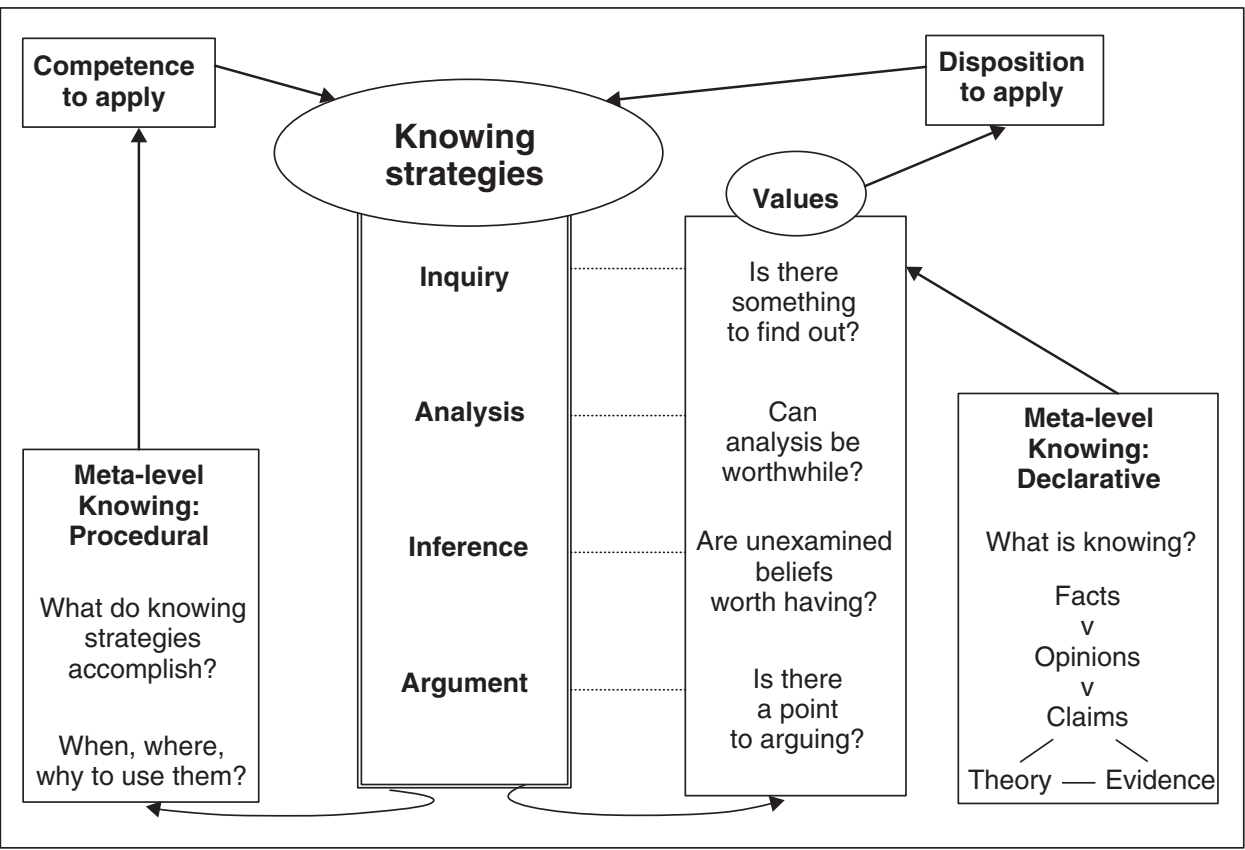

FIG URE 4 | Kuhn's ${ }^{30}$ theory of intellectual competence includes influences of both meta-cognition and dispositional factors. The interaction of these factors results in theory creation and evaluation. (Reprinted with permission from Ref 30. Copyright 2001 Wiley-Blackwell.)

distinct animal categories (e.g., dog and cat) but happily accept grouping together members of two distinct artifact categories (e.g., bookcase and table). ${ }^{35}$

Children are also more likely to generalize properties of an individual to members of the broader category for animals than for artifacts, suggesting that animal categories capture a greater wealth of deep, nonobvious commonalities than artifact categories. ${ }^{39}$ Altogether, for young children as well as adults, the process of categorization involves distinct kinds of information, structure, and inferences depending on the domain (animal versus artifact). ${ }^{40,41}$ Sloman et al. ${ }^{42}$ provide a thoughtful discussion of different theoretical accounts of domain-specific categorization.

\section{IMPLICATIONS FOR COGNITIVE DEVELOPMENT}

Domain-specific theories challenge the conventional wisdom that development proceeds along a series of discrete stages reflecting broad, overarching changes in the structure of thought. ${ }^{10}$ Stage theorists posit maturational limits on the capacities of children as a function of age. On this view, a 12-year-old is a fundamentally different kind of learner and thinker than a 7-year-old, who in turn is a fundamentally different kind of learner and thinker than a 4-yearold (and so on)-regardless of the content of the information being considered. In contrast, the past 40 years of research documents that learning and cognitive performances are uneven across domains within an age. More generally, it is misleading to characterize young children as qualitatively distinct reasoners from adults. Children are not uniformly concrete thinkers, solely focused on surface appearances, incapable of considering subtle or nonobvious features. Preschool children can distinguish appearance from reality, ${ }^{43}$ reason about abstract categories, ${ }^{29}$ and consider nonobvious entities such as germs or invisible forces. ${ }^{44,45}$ Children often default to considering outward appearances in the absence of relevant domain-specific information, but they are not limited to such cues.

Another central debate in the area of cognitive development concerns how best to characterize conceptual change. We know that concepts undergo changes with age, but what is the nature of such change? Do children simply accrue greater amounts of knowledge over time (the continuity view), or do children's concepts undergo fundamental restructuring or reorganization, leading to wholly new concepts that are incommensurate with old concepts (the discontinuity view)? Carey ${ }^{22}$ has provided compelling evidence for theory change in childhood akin to theory change in science, arguing, p. $18^{46}$ : 'human beings, alone among animals, have the capacity to create representational systems that transcend sensory representations and core cognition... [they] create new representational resources that are qualitatively different from the representations they are built from'. 
There is evidence for qualitative conceptual change in domains as wide-ranging as number, object kinds, social kinds, matter/substance, and heat/temperature. For example, Carey ${ }^{46}$ presents extensive evidence that although infants have an innate capacity to represent quantities (a) parallel individuation system that represents individuals and so permits solving simple addition and subtraction problems, ${ }^{47}$ they do not yet have the capacity to represent positive integers, and this ability takes years to develop.

A theory perspective on cognition also emphasizes the role of input to developing theories. There are several types of input leading to children's theory enrichment and theory change. One important sort of input is children's direct observations of the environment (e.g., observing different kinds of faces influences the nature of perceptual face categories $)^{48}$ as well as their own manipulations on the environment (e.g., the opportunity to pick up objects influences an infant's understanding of intentional action). ${ }^{49}$ Input to children's developing theories also includes the language and social guidance of others. ${ }^{50,51}$ Indeed, humans may be uniquely prepared to consider and respond to the pedagogical cues of conspecific others. ${ }^{52}$ Notably, children do not simply or passively absorb information from others, but rather interpret and assess informational cues. ${ }^{53}$ For example, they consider the trustworthiness and knowledgeability of the source, in judging whom to believe.

Furthermore, theory change entails correcting misconceptions-which can be persistent-and thus children cannot just simply add on correct information as presented by others. For example, when learning about the shape of the earth, elementary-school children first have to learn that their a priori assumptions (e.g., that earth is a hollowed-out sphere with people living on the inside) are erroneous. ${ }^{54}$

The naïve theory perspective also emphasizes the importance of explanation as a critical process in children's reasoning. Explanation is verbally demanding, and children often display much more sensitive understanding when nonverbal methods are used (e.g., simple choice tasks; habituation; eyetracking). Nonetheless, despite the linguistic and cognitive demands of constructing explanations, recent evidence suggests that explanations may at times promote a more accurate and considered understanding of the task at hand, at least on an explicit level. For example, when asked to reason about theory of mind, children provide a deeper understanding of false beliefs when asked to explain a character's action ('Why did Jimmy look under the couch when his cat is actually behind the chair?') than when asked to predict a character's action ('Where will Jimmy look for his cat?'). ${ }^{55}$ Likewise, children provide a more accurate understanding of contamination when asked to explain a character's action ('Why did Sally drink the water instead of the lemonade with a leaf in it?') than when asked to predict a character's action ('What will Sally drink: the water or the lemonade with a leaf in it?'). ${ }^{56}$ Interestingly, when providing explanations, they spontaneously refer to invisible elements that were never mentioned in the story (e.g., germs or contamination, see Table 4). It is counter-intuitive that explanations can be more sensitive routes to children's understanding than predictions, but explanation assumes a particular outcome, and is thus more constrained than prediction. An intriguing possibility is that the act of generating an explanation may itself promote better causal understanding. ${ }^{57}$ Wellman and

TABLE 4 | Examples of Children's Explanations of Disease Transmission (Reprinted with permission from Ref 17. Copyright 2004 Willey-Blackwell)

\begin{tabular}{|c|c|c|c|}
\hline Germs-transmission & Disgust-transmission & Contaminating Substance Transfer & Dirt or Dirty Substance Transfe \\
\hline $\begin{array}{l}\text { 'Because this one has the germs } \\
\text { from the dog on it. Dog took a } \\
\text { lick, they spread germs on each } \\
\text { other and the boy gets sick' }\end{array}$ & $\begin{array}{l}\text { 'If she eats it then there's mud, } \\
\text { because the chocolate chip } \\
\text { cookie fell in the mud, there } \\
\text { would be mud in her mouth, } \\
\text { since there's also bugs in } \\
\text { mud, that's gross' }\end{array}$ & $\begin{array}{l}\text { 'Maybe the grasshopper has a } \\
\text { color on its skin that got in the } \\
\text { pop and made it poisonous. } \\
\text { Maybe the grasshopper hopped } \\
\text { in and left green stuff' }\end{array}$ & $\begin{array}{l}\text { 'It fell in the dirt, there's } \\
\text { little animals in there; } \\
\text { little animals climb in } \\
\text { there' }\end{array}$ \\
\hline $\begin{array}{l}\text { 'Because the dirt is dirty and she } \\
\text { doesn't want to get sick. Dirt } \\
\text { has yucky germs on it and that's } \\
\text { where the worms are' }\end{array}$ & $\begin{array}{l}\text { 'Cause there's doggy lick in } \\
\text { there; because it would taste } \\
\text { gross' }\end{array}$ & $\begin{array}{l}\text { 'Cause he knew the grasshopper } \\
\text { jumped in and jumped out. } \\
\text { 'Cause it doesn't taste good; } \\
\text { that kind of grasshopper flavor } \\
\text { doesn't taste good' }\end{array}$ & $\begin{array}{l}\text { 'Because the leaf came in } \\
\text { and fogged the milk and } \\
\text { got it all dirty. It just dirty } \\
\text { cause the leaf came in' }\end{array}$ \\
\hline $\begin{array}{l}\text { 'Because he doesn't want to get } \\
\text { dog germs, they will make him } \\
\text { definitely sick. Dogs have dirty } \\
\text { tongues like worms' }\end{array}$ & $\begin{array}{l}\text { 'Because of the leaf, cause they } \\
\text { are yucky for you. You get } \\
\text { icky stuff in your tummy' }\end{array}$ & $\begin{array}{l}\text { 'He wanted the grape because he } \\
\text { wouldn't want doggy slime in } \\
\text { his mouth. He would have to go } \\
\text { to the doctor' }\end{array}$ & $\begin{array}{l}\text { 'Because the chocolate milk } \\
\text { was dirty cause the leaf } \\
\text { fell in, the leaf can crack } \\
\text { and a piece can fall off' }\end{array}$ \\
\hline
\end{tabular}


$\mathrm{Liu}^{58}$ refer to this process as 'post-diction'. More research is needed to uncover the mechanisms by which post-diction differs from verbally stated predictions, and how both of these processes differ from implicit predictions of the sort made in infancy. ${ }^{59}$

\section{INTERACTIONS AMONG DOMAINS}

The organization of knowledge into domains raises the question of how domains interact. To what extent do children rely on domain boundaries in their reasoning? To what extent do distinct explanatory models compete versus coexist? This problem is particularly acute when one considers that real-world phenomena are more complex than a strict division into domains might suggest. Although we tend to prefer single explanations, ${ }^{60}$ a given phenomenon may call to mind multiple possible accounts. For example, an individual's serious illness may be understood in terms of frameworks that are biological (infection), psychological (stress), political (environmental toxins found in poor neighborhoods), sociological (effects of institutional racism or sexism on one's immune system), supernatural (witchcraft or prayer), moral (divine retribution), statistical (bad luck), etc.

On the one hand, children honor strict ontological boundaries from an early age (e.g., biological versus psychological). ${ }^{32,37}$ Notably, children not only accurately represent domain distinctions that are a realistic reflection of regularities found in the world, but also overextend the importance of ontological boundaries, erroneously rejecting real-life phenomena that cross domain boundaries. For example, adults and children alike have difficulty appreciating psychogenic illnesses ${ }^{61}$ : children under age 10 deny, for example, that a mental state can have physical effects (e.g., that worry can lead to a stomach-ache), whereas adults accept psychogenic illnesses but treat them as not 'real' (e.g., medicine cannot cure bodily disorders, if they are caused by a mental state). These beliefs are resistant to informational input, but also modified by such input. When provided with statistical evidence that runs counter to this theoretical assumption, children as young as 3.5 years of age can learn that a psychological cause had physical effects. ${ }^{62,63}$

On the other hand, children also at times make the opposite error of inappropriately assuming that one domain intrudes upon another. For example, when making predictions about how objects behave in accordance with physical laws (e.g., the path that an object will fall out of an airplane, the trajectory of an object launched off a slide, or the weight of an object on the moon), 5- and 7-year-old children inappropriately take into account the animacy of the physical object-for example, they generalized a physical fact about a rock more often to another inanimate object than to a person, and vice versa. ${ }^{64}$ A second example of inappropriate intrusion of one domain onto reasoning about another comes from children's judgments about ownership. When deciding who can be an owner, children inappropriately take into account a person's psychological state. ${ }^{65}$ For example, adults attribute ownership to individuals who are awake or asleep, but children, despite understanding the nature of sleep as a mental state quite well, only attribute ownership to people who are awake. Children and adults attribute the same physical and mental abilities and limitations to sleeping people, but these limitations interfere with ownership attributions made by children. Altogether, these disparate pieces of evidence suggest that there is not a single approach to reasoning about relations among domains, and that children are relatively openminded in this regard.

Another key question is whether learning a new theory results in the new theory supplanting the old, such that the old theory disappears, or whether instead the new theory coexists alongside the old theory. Increasing evidence suggests that the latter possibility holds true. One widespread example is that acquiring scientific theories to explain phenomena such as illness or species origins does not eradicate supernatural or religious theories for the same phenomena. Subbotsky, pp. 327-328, explains this perspective as follows:

'... a contemporary Western individual is not an exclusively rational being and ... he or she, living in the world created by science, dwells in the worlds of dreams, art, fantasies, play, and social myths. This means that if the individual is to encounter a certain phenomenon with no established scientific explanation, he or she may be prepared to explain the phenomenon in a number of ways, only some of which are compatible with the vision of modern science. ${ }^{66}$

Dunbar et al. ${ }^{67}$ similarly note that, p. 202, 'even when conceptual change appears to have taken place, students still have access to the old naive theories and... these theories appear to be actively inhibited rather than reorganized and absorbed into the new theory'. Dunbar and colleagues conducted a study with undergraduates, using fMRI measures to examine their theories of physical motion. Prior research has uncovered a well-documented tendency for people to maintain a medieval 'Impetus' theory of motion (e.g., larger object falls faster than smaller object), and to require extensive schooling to shift to a more accurate 'Newtonian' theory of motion (e.g., larger and smaller objects fall at the same rate). ${ }^{68}$ 
In Dunbar et al.'s ${ }^{67}$ study, participants were asked to predict kinds of motion, and also were scanned while viewing videos consistent with either the Impetus theory or the Newtonian theory. Overall, amount of physics experience predicted both participants' predictions and their brain responses. Participants showed increased patterns of activation in the anterior cingulate when viewing the motion pattern inconsistent with their naïve theory (e.g., nonphysics students predicted that larger objects would fall faster, and showed an error detection brain pattern when larger and smaller objects fell at the same rate; physics students predicted that objects would fall at the same rate, and showed an error detection brain pattern when they did not). But of particular interest in the present context, a subset of the participants who gave the correct prediction nonetheless showed increased activation of the anterior cingulate when viewing this pattern. Dunbar et al. suggest that these participants have learned the correct response without understanding why or undergoing the deep conceptual change required for theory revision - thereby maintaining the old, intuitive theory while accepting the new, more scientific theory.

Another example of coexistence of biological and supernatural explanatory systems is found in illness concepts, where the desire to find an explanatory account is high, and especially when multiple explanatory models are available in the input. For example, children and adults in Sesotho-speaking communities in South Africa, where HIV infection rates are very high, maintain both biological and supernatural (witchcraft) explanatory systems. ${ }^{69}$ In a study examining illness beliefs in this population, over half the participants provided both biological and supernatural explanations at least once. Furthermore, one of the communities in this study was less rural and had higher levels of biological knowledge, but this did not relate inversely to frequency of witchcraft explanations. Thus, endorsement of witchcraft does not reflect an absence of accurate biological explanations. Instead, witchcraft beliefs persisted even when participants had ample knowledge of the biological processes involved in illness transmission.

Legare and Gelman ${ }^{69}$ proposed that there are at least three possibilities for how natural and supernatural explanatory frameworks may coexist with one another: (1) they may remain distinct frameworks recruited to explain distinct phenomena (e.g., natural explanations to explain colds; supernatural explanations to explain AIDS), (2) they may be used jointly to explain the same phenomena, but loosely (without considering how they interact), or (3) they may combine more precisely (e.g., treating natural causes as proximate but supernatural causes as distal). The evidence best supports the second and third options-that is, that natural and supernatural beliefs are often recruited to explain the same event. Adults' justifications yielded support for both 'loose' coexistence (supplying both kinds of explanations without trying to integrate them; for example, explaining an illness event by saying, 'adultery and witchcraft') and more precise coexistence (e.g., explaining an illness event by saying, 'Witchcraft can fool you into sleeping with an HIV-infected person' or 'A witch can make a condom weak, and break').

A further point regarding the coexistence of multiple explanatory systems is that context is critical in determining how an individual (child or adult) understands a phenomenon and which causal theory they invoke. This has been found for explanations for illness, ${ }^{69,70}$ explanations for death, ${ }^{71}$ judgments about category membership, ${ }^{72}$ and judgments about magical or fantasy events. ${ }^{73}$ In all of these cases, we see markedly different responses as a function of context. These results suggest that coherence in theories may be difficult to achieve across learning contexts. For other investigations of coexistence of multiple explanatory frameworks, see Refs 74 and 75.

\section{CONCLUSION}

We have reviewed evidence demonstrating that domain-specific reasoning has abundant effects on human thought, from infancy through adulthood. Domain-specificity can result from any of multiple sources, including innate biases, extensive experience, and expertise, and the construction of intuitive causal theories. We focused on causal theories, as these have implications for cognitive development and conceptual change.

Although we have presented evidence consistent with the view that children construct domain-specific theories, not everyone subscribes to the theory theory perspective. For example, considering 'theory of mind', some researchers ascribe more innate competence to infants and suggest that apparent instances of theory change instead reflect changes in executive function. ${ }^{76}$ In the causal reasoning and categorization literature, some researchers subscribe to the view that children's learning is fragile, context dependent, and driven by associative learning of primarily salient, surface properties. ${ }^{77-79}$ A different perspective, supported by promising new statistical approaches to rational inference, suggests the possibility of drawing rich abstract inferences from sparse data, consistent with the theory theory approach. Furthermore, even those who endorse the theory theory do not suggest that 
domain-general cognitive processes are unimportant. Attentional biases, similarity judgments, and associative learning all play important roles in many aspects of cognition and cognitive development. Debates concerning precisely what this role is continue to generate novel experimental tests and insights.

Another open question concerns what constitutes a domain, from a psychological perspective. Although it can be convenient to think of domains in terms of disciplines in a university (e.g., physics, psychology, biology), it may turn out that certain domain distinctions are more subtle or fine-grained than previously understood. For example, New et al. ${ }^{80}$ find that spatial reasoning is not a single, undifferentiated domain, but rather consists of more specific tasks that have different functional implications during key periods of human evolutionary history. Thus, although some studies have found that men perform better on spatial reasoning tasks than women, these effects reverse when the task involves gathering high-calorie foods in a context with landmarks (e.g., recalling the order and location of avocado and honey in an outdoor farmer's market). Furthermore, domainspecificity may be fruitfully extended to other areas of psychological functioning, beyond knowledge representations. For example, the kinds of interpersonal social interactions, including parent-child interactions, may be understood in a domain-specific framework. ${ }^{81}$
The available evidence points to several directions for future research. One important direction is to make use of new methods and approaches to broaden the empirical basis for studying domainspecificity. One such approach is to make judicious use of neuroimaging and brain localization data to obtain converging evidence for the underlying processes that distinguish between domains. Exciting studies examining these issues when studying theory of mind suggest important conclusions regarding the processes involved. ${ }^{82}$ Another approach is to make use of evidence from different cultural groups to disentangle effects of experience on domain-specific learning. ${ }^{83,84}$

Another future research direction is to try to understand the developmental underpinnings of domain-specificity, and in particular, the extent to which the divisions into domains are innately given versus constructed in development. A challenge in this area is to determine a nonverbal equivalent to theories in infancy (see the work of Onishi and Baillargeon ${ }^{85}$ for an excellent example of theory of mind reasoning in preverbal infancy). Relatedly, an important issue is that of understanding how innate (or early) biases interact with statistical learning to yield theory growth and change. ${ }^{86}$ These questions hold great promise for addressing some of the key foundational issues in psychology.

\section{REFERENCES}

1. Miller GA. The magical number seven, plus or minus two: some limits on our capacity for processing information. Psychol Rev 1956, 63:81-97.

2. Newport EL. Critical periods in language development. In: Nadel L, ed. Encyclopedia of Cognitive Science. London: Macmillian; 2002.

3. Ro T, Russell C, Lavie N. Changing faces: a detection advantage in the flicker paradigm. Psychol Sci 2001, 12:94-99.

4. Sakamoto Y, Love BC. Schematic influences on category learning and recognition memory. J Exp Psychol Gen 2004, 133:534-553.

5. Coley JD, Hayes B, Lawson C, Moloney M. Knowledge, expectations, and inductive reasoning within conceptual hierarchies. Cognition 2004, 90:217-253.

6. Meltzoff AN. Understanding the intentions of others: re-enactment of intended acts by 18 -month-old children. Dev Psychol 1995, 31:838-850.

7. Woodward AL. Infants selectively encode the goal object of an actor's reach. Cognition 1998, 69:1-34.

8. Chase WG, Simon HA. Perception in chess. Cogn Psychol 1973, 4:55-81.
9. Chase WG, Ericsson KA. Skill and working memory. In: Bower G, ed. The Psychology of Learning and Motivation. New York: Academic Press; 1982.

10. Piaget J. Genetic Epistemology. New York: Columbia University Press; 1970.

11. Wason PC, Johnson-Laird PN. The Psychology of Deduction: Structure and Content. Cambridge: Harvard University Press; 1972.

12. Cheng P, Holyoak K. Pragmatic reasoning schemas. Cogn Psychol 1985, 17:391-416.

13. Cosmides L. The logic of social exchange: has natural selection shaped how humans reason? Studies with the Wason selection task. Cognition 1989, 31:187-276.

14. Wellman HM, Gelman SA. Knowledge acquisition in foundational domains. In: Damon W, Kuhn D, Siegler RS, eds. Handbook of Child Psychology. New York: John Wiley \& Sons; 1998.

15. Kanwisher NG, Yovel G. Face perception. In: Bernston GG, Cacioppo JT, eds. Handbook of Neuroscience for the Behavioral Sciences. New Jersey: John Wiley \& Sons; 2009, 841-858. 
16. Feigenson L, Dehaene S, Spelke ES. Core systems of number. Trends Cogn Sci 2004, 7:307-314.

17. Pinker S. The Language Instinct. New York: W. Morrow; 1994.

18. Cosmides L, Tooby J. Unraveling the enigma of human intelligence: evolutionary psychology and the multimodular mind. In: Sternberg RJ, Kaufman JC, eds. The Evolution of Intelligence. Hillsdale: Erlbaum; 2001.

19. Ericsson KA. Recent advances in expertise research: a commentary on the contributions to the special issue. Appl Cogn Psychol 2005, 19:233-241.

20. Gopnik A, Meltzoff AN. Words, Thoughts, and Theories. Cambridge: Bradford, MIT Press; 1997.

21. Baillargeon R. Infants' understanding of the physical world. In: Sabourin M, Craik F, Robert M, eds. Advances in Psychological Science. vol. 2. London: Psychology Press; 1998.

22. Carey S. Conceptual Change in Childhood. Cambridge: Bradford, MIT Press; 1985.

23. Spelke ES, Phillips AT, Woodward AL. Infants' knowledge of object motion and human action. In: Sperber D, Premack D, eds. Causal Cognition: A Multidisciplinary Debate. New York: Oxford University Press; 1995.

24. Kushnir T, Gopnik A. Children infer causal strength from probabilities and interventions. Psychol Sci 2005, 16:678-683.

25. Ahn W, Kim NS, Lassaline ME, Dennis MJ. Causal status as a determinant of feature centrality. Cogn Psychol 2000, 41:361-416.

26. Gopnik A, Sobel D. Detecting blickets: how young children use information about novel causal powers in categorization and induction. Child Dev 2000, 71: 1205-1222.

27. Legare $\mathrm{CH}$, Gelman SA, Wellman HM. Inconsistency with prior knowledge triggers children's causal explanatory reasoning. Child Dev 2010, 81:929-944.

28. Wellman HM. The Child's Theory of Mind. Cambridge: MIT Press; 1990.

29. Gelman SA. The Essential Child: Origins of Essentialism in Everyday Thought. New York: Oxford University Press; 2003.

30. Kuhn D. How do people know? Psychol Sci 2001, $12: 1-8$

31. Gopnik A, Wellman HM. The "theory theory". In: Hirschfield L, Gelman S, eds. Domain Specificity in Culture and Cognition. New York: Cambridge University Press; 1994.

32. Inagaki K, Hatano G. Young Children's Nä̈ve Thinking about the Biological World. New York: Psychology Press; 2002

33. Xu F. Language acquisition and concept formation: count nouns and object kinds. In: Gaskell G, ed. Handbook of Psycholinguistics. Oxford: Oxford University Press; 2007.
34. Gould SJ. Wonderful Life: The Burgess Shale and the Nature of History. New York: Norton; 1989.

35. Rhodes M, Gelman SA. A developmental examination of the conceptual structure of animal, artifact, and human social categories across two cultural contexts. Cogn Psychol 2009, 59:244-274.

36. Gelman SA, Markman EM. Categories and induction in young children. Cognition 1986, 23:183-209.

37. Keil FC. Concepts, Kinds, and Cognitive Development. Cambridge: MIT Press; 1989.

38. Rhodes M, Gelman SA. Five-year-olds' beliefs about the discreteness of category boundaries for animals and artifacts. Psychon Bull Rev 2009, 16:920-924.

39. Brandone AC, Gelman SA. Differences in preschoolers' and adults' use of generics about novel animals and artifacts: a window onto a conceptual divide. Cognition 2009, 110:1-22.

40. Grief ML, Kemler Nelson DG, Keil FC, Gutierrez F. What do children want to know about animals and artifacts? Domain-specific requests for information. Psychol Sci 2006, 17:455-459.

41. Booth AE, Waxman SR. Word learning is 'smart': evidence that conceptual information effects preschoolers' extension of novel words. Cognition 2002, 84:B11-B22.

42. Sloman S, Lombrozo T, Malt B. Ontological commitments and domain-specific categorization. In: Roberts MJ, ed. Integrating the Mind: Domain General Versus Domain Specific Processes in Higher Cognition. Hove: Psychology Press; 2007.

43. Deak DO. Do children really confuse appearance and reality? Trends Cogn Sci 2006, 10:546-550.

44. Kalish CW. Preschoolers' understanding of germs as invisible mechanisms. Cogn Dev 1996, 11:83-106.

45. Saxe R, Tenebaum JB, Carey S. Secret agents: inferences about hidden causes by 10 - and 12-month-old infants. Psychol Sci 2005, 16:995-1001.

46. Carey S. The Origin of Concepts. New York: Oxford University Press; 2009.

47. Wynn K. Addition and subtraction by human infants. Nature 1992, 358:749-750.

48. Kelly DJ, Liu S, Lee K, Quinn PC, Pascalis O, Slater AM, Ge L. Development of the other-race effect in infancy: evidence towards universality? J Exp Child Psychol 2009, 104:105-114.

49. Sommerville JA, Woodward AL, Needham A. Action experience alters 3-moth-old infants' perception of others' actions. Cognition 2005, 96:B1-B11.

50. Gelman SA. Learning from others: children's construction of concepts. Annu Rev Psychol 2009, 60:115-140.

51. Koenig MA, Harris PL. Preschoolers mistrust ignorant and inaccurate speakers. Child Dev 2005, 76: 1261-1277.

52. Gergely G, Csibra G. Natural pedagogy. Trends Cogn Sci 2009, 13:148-153. 
53. Jaswal VK. Don't believe everything you hear: preschoolers' sensitivity to speaker intent in category induction. Child Dev 2004, 75:1871-1885.

54. Vosniadou S, Brewer WF. Mental models of the earth: a study of conceptual change in childhood. Cogn Psychol 1992, 24:535-585.

55. Bartsch K, Wellman HM. Children Talk About the Mind. New York: Oxford University Press; 1997.

56. Legare CH, Wellman HM, Gelman SA. Evidence for an explanation advantage in naïve biological reasoning. Cogn Psychol 2009, 58:177-194.

57. Amsterlaw J, Wellman H. Theories of mind in transition: a microgenetic study of the development of false belief understanding. J Cogn Dev 2006, 7:139-172.

58. Wellman HM, Liu D. Causal reasoning as informed by the early development of explanations. In: Gopnik A, Schulz LE, eds. Causal Learning: Psychology, Philosophy, Computation. New York: Oxford University Press; 2007.

59. Southgate V, Senju A, Csibra G. Action anticipation through attribution of false belief by 2-year-olds. Psychol Sci 2007, 18:587-592.

60. Lombrozo T. Simplicity and probability in causal explanation. Cogn Psychol 2007, 55:232-257.

61. Notaro PC, Gelman SA, Zimmerman MA. Children's understaning of psychogenic bodily reaction. Child Dev 2003, 72:444-459.

62. Schulz LE, Bonawitz EB, Griffiths TL. Can being scared cause tummy aches? Naïve theories, ambiguous evidence, and preschoolers' causal inferences. Dev Psychol 2007, 43:1124-1139.

63. Bonawitz EB, Fischer A, Schulz LE. Teaching three-anda-half year olds to reason about ambiguous evidence. $J$ Cogn Dev; In press.

64. Heyman G, Phillips A, Gelman S. Children's reasoning about physics within and across ontological kinds. Cognition 2003, 89:43-61.

65. Noles NS, Keil FC, Bloom P, Gelman SA. Children's intuitions about who can own things; submitted.

66. Subbotsky E. Causal reasoning and behavior in children and adults in a technologically advanced society: are we still prepared to believe in magic and animism? In: Mitchell P, Riggs KJ, eds. Children's Reasoning and the Mind. Hove: Psychology Press; 2000.

67. Dunbar K, Fugelsang J, Stein C. Do naïve theories ever go away? In: Lovett M, Shah P, eds. Thinking with Data: 33rd Carnegie Symposium on Cognition. Mahwah, NJ: Erlbaum; 2007.

68. McCloskey M. Intuitive physics. Sci Am 1983, 248: $122-130$.

69. Legare CH, Gelman SA. Bewitchment, biology, or both: the co-existence of natural and supernatural explanatory frameworks across development. Cogn Sci 2008, 32:607-642.
70. Nguyen S, Rosengren K. Causal reasoning about illness: a comparison between European and VietnameseAmerican children. J Cogn Cult 2004, 4:51-78.

71. Harris PL, Gimenez M. Children's acceptance of conflicting testimony: the case of death. J Cogn Cult 2005, 5:143-164.

72. Walker SJ. Supernatural beliefs, natural kinds, and conceptual structure. Mem Cognit 1992, 20:655-662.

73. Woolley JD, Van Reet J. Effects of context on judgments concerning the reality status of novel entities. Child Dev 2006, 77:1778-1793.

74. Rosengren KV, Johnson CN, Harris PL. Imagining the Impossible: Magical, Scientific, and Religious Thinking in Children. Cambridge: Cambridge University Press; 2000.

75. Hood B. Supersense: Why We Believe in the Unbelievable. New York: HarperCollins; 2009.

76. Leslie AM, Friedman O, German TP. Core mechanisms in 'theory of mind'. Trends Cogn Sci 2004, 8:528-533.

77. Rakison DH, Poulin-Dubois D. The developmental origin of the animate-inanimate distinction. Psychol Bull 2001, 2:209-228.

78. Sloutsky VM, Fisher AV. Induction and categorization in young children: a similarity-based model. J Exp Psychol Gen 2004, I133:166-188.

79. Smith LB. How domain-general processes may create domain-specific biases. In: Bowerman M, Levinson SC, eds. Language Acquisition and Conceptual Development. Cambridge: Cambridge University Press; 2001.

80. New J, Krasnow MM, Truxaw D, Gaulin SJ. Spatial adaptations for plant foraging: women excel and calories count. Proc R Soc B 2007, 274:2679-2684.

81. Grusec JE, Davidov M. Integrating different perspectives on socialization theory and research: a domainspecific approach. Child Dev 2010, 81:687-709.

82. Young L, Dodell-Feder D, Saxe R. What gets the attention of the temporo-parietal junction? An fMRI investigation of attention and theory of mind. Neuropsychologia 48:2658-2664.

83. Medin DL, Atran S. The native mind: biological categorization, reasoning and decision making in development across cultures. Psychol Rev 2004, 111:960-983.

84. Nisbett RE, Peng K, Choi I, Norenzayan A. Culture and systems of thought: holistic vs. analytic cognition. Psychol Rev 2001, 108:291-310.

85. Onishi KH, Baillargeon R. Do 15-month-old infants understand false beliefs? Science 2005, 308:255-258.

86. Xu F, Tenenbaum JB. Word learning as Bayesian inference. Psychol Rev 2007, 114:245-272. 